\title{
Differential conditioning as a function of exposure time to discriminative and nondiscriminative cues preceding response*
}

\author{
STEPHEN F. DAVIS $\dagger$ \\ Austin Peay State University, Clarksville, Tennessee 37040 \\ and \\ H. WAYNE LUDVIGSON \\ Texas Christian University, Fort Worth, Texas 76129
}

\begin{abstract}
Five groups of rats received differential conditioning to large and small reward in a straight runway. Three groups were confined to startbox for 0,2 , or $8 \mathrm{sec}$ prior to the opportunity to traverse the runway, with no preresponse discriminative cues to signal reward magnitude until admission to the runway. Two additional groups received the discriminative cues for 2 or 8 sec while confined in the startbox. All Ss learned the discrimination, though the sharp depression in performance to $\mathrm{S}-$ found in certain other studies failed to appear. Discriminative cue presentation in the startbox did not influence performance. Together, these facts suggest that preresponse cues only influence a frustrative depression to $\mathrm{S}-$, and that for unknown reasons such a depression failed to appear in this study. Startbox confinement depressed performance to both rewards, with longer durations producing greater depressions.
\end{abstract}

It is common in the area of differential conditioning to find that speed of approach to a small reward ( $\mathrm{S}-$ ) in one situation (e.g., a black runway) is depressed when Ss experience a large reward ( $\mathrm{S}+$ ) in a second situation (e.g., a white runway). This phenomenon has been termed a "negative contrast effect" (NCE). Studies by Ludvigson and Gay (1967) and Peckham and Amsel (1967) have been instrumental in determining that the mode of presentation of the discriminative cues is important in the development and magnitude of the NCE. These studies indicated that depression of performance to $\mathrm{S}$ that was especially pronounced in the start measure was displayed by Ss that started from a common neutral startbox. When different startboxes (that matched the color of the alley they preceded) or a transparent start door were used, performance to $\mathrm{S}$ - was much less depressed. Thus, it would appear that giving a differential cue (i.e., a cue signaling the impending reward magnitude) prior to opportunity for the instrumental response can reduce the NCE that is typically observed in the traditional latency measures. A study reported by Davis, Gilbert, and Seaver (1971) was consistent with these data and further suggested that, given enough time in the presence of the cues, all discrimination disappears.

*This work was supported in part by a National A eronautics and Space Administration Traineeship to the first author, and by U. S. Public Health Service Grant MH1 3314 and a grant from the Texas Christian University Research Foundation to the second author.

†This paper is based upon portions of a dissertation submitted to the Graduate School, Texas Christian University, in partial fulfillment for the requirements for the $\mathrm{PhD}$ degree.
The present experiment was designed to assess further, in an instrumental differential conditioning task, the effect of variation in amount of exposure to discriminative cues prior to opportunity for the response. Second, the effect of variation in startbox confinement time without discriminative cues present was investigated.

\section{METHOD}

\section{Subjects}

The Ss were 90 experimentally naive female albino rats purchased from the Charles River Breeding Labs, Wilmington, Massachusetts. The experiment was conducted in two replications using $45 \mathrm{Ss}$ each. The Ss were approximately 90 days old at the beginning of each replication. All Ss were housed in individual cages with water always available.

\begin{abstract}
Apparatus
The apparatus consisted of a straight runway $91.44 \mathrm{~cm}$ in length. The runway was serviced by a $26.67-\mathrm{cm}$ startbox. The runway was $8.89 \mathrm{~cm}$ wide and tapered to a $5.80-\mathrm{cm}$ width where the startbox joined the runway. The startbox was $5.80 \mathrm{~cm}$ wide. Both the startbox and runway were $10.16 \mathrm{~cm}$ high and were covered with clear Plexiglas lids. The entire apparatus was painted white. A "sky" made of translucent matte acetate was located $121.92 \mathrm{~cm}$ above the runway. Located $45.72 \mathrm{~cm}$ above the sky were $457-\mathrm{W}$ lamps. These lamps were connected to a Micronta variable transformer which allowed the $\mathrm{E}$ to vary the voltage across the lamps from 0 to $140 \mathrm{~V}$ and so present discriminative stimuli to a $S$ in the apparatus. Three photoelectric beams were located at $30.48-\mathrm{cm}$ intervals in the runway. These, in conjunction with a microswitch activated by raising the start door, yielded start, run, and goal times. Reciprocation of these time measures and multiplication by the
\end{abstract}




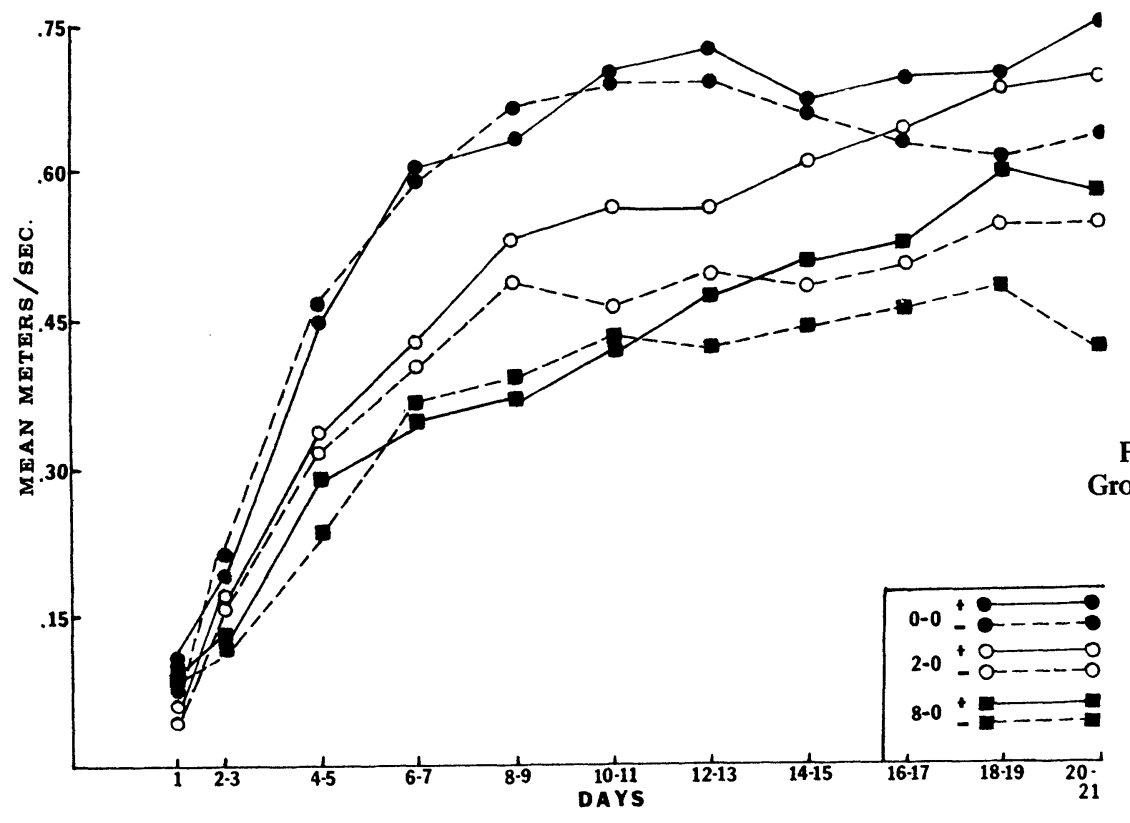

appropriate constant resulted in start, run and goal speeds in meters/sec.

\section{Procedure}

Upon receipt from the supplier, the Ss in each replication were given unlimited food and water for 1 week, and then the deprivation schedule was initiated. After 2-weeks experience with the deprivation schedule (Days 1-14), the Ss were randomly assigned to five equal groups designated: $0-0,2-0,8-0,2-2$, and $8-8$. Three equal squads were formed by random assignment of three Ss from each group. The order in which these squads received their treatments within a day was randomly determined and remained constant across days for the duration of the experiment. The Ss in each squad were fed $10 \mathrm{~min}$ after the completion of the daily experimental session for that squad.

The first number of each group designation refers to the startbox confinement time in seconds. The second number designates the length of time in seconds that the discriminative cues were presented during the startbox confinement interval. "Discriminative cues" refers to the level of illumination of the overhead lamps arising from the application of 30 or $120 \mathrm{~V}$ of electricity. The assignment of voltages as discriminative cues was random with the exception that onehalf of the $S$ s in each group had the $30-\mathrm{V}$ cue as the large reward (S+) stimulus and the other half had the $120-\mathrm{V}$ stimulus as the $\mathrm{S}+$ stimulus.

Days 15-17 constituted a pretraining phase for all Ss. Habituation to the reward pellets was permitted on Days 15-17 by incorporating $1037-\mathrm{mg}$ food pellets (P. J. Noyes, Company; Formula A) into the daily ration. On Days 16-17 the Ss were transported, one squad at a time, into the experimental room where each $\mathrm{S}$ received a 2-min handling period during which it was gently stroked across the back, picked up, and set down several times. Following this handling period, each $\mathrm{S}$ was placed into the runway for 5-min exploration period during which all doors were raised, photorelay equiment was operative, reward was absent, and the overhead lighting was set at an intermediate level $(60 \mathrm{~V})$.

On Days 18-38 (84 trials) all Ss received two S+ (15, 37-mg pellets) and two $\mathrm{S}-$ (one, $37-\mathrm{mg}$ pellet) training trails per day. On all trials the Ss were placed into the startbox under the intermediate level of illumination $(60 \mathrm{~V})$, and, following the appropriate time interval, the illumination was abruptly changed to the $\operatorname{dim}(30 \mathrm{~V})$ or bright $(120 \mathrm{~V})$ discriminative level. Timing of the confinement duration and discriminative cue presentation began immediately upon placement of the $S$ into the startbox. At the end of the confinement interval, the start door was raised and the $S$ allowed to traverse the runway. If a $60-\mathrm{sec}$ response time was registered on any clock the $S$ was gently moved into the next clock section and a 60 -sec time recorded. Ss were removed from the goalbox as soon as the last piece of food was taken into the mouth.

The order in which Ss within a squad received a trial was random and constant for the four daily trials, yielding an intertrial interval for a given $S$ of approximately 20 min after the initial slow trials. All six possible daily sequences of $\mathrm{S}+$ and $\mathrm{S}-$ trials $(+--+,++--,--++,-++-,+-+-$, and -+-+$)$ were used. These sequences were randomly assigned to individual Ss with the restriction that no sequence could occur more than twice in succession.

The possibility of odor contamination (see Ludvigson \& Sytsma, 1967) was counteracted in two ways. First, air from the goalbox, entering the alley primarily through openings in the startdoor, was exhaused by a fan. The air passed over a cake of "Solidaire" deodorant material (Airkem Corporation) located in a container fastened to the start door. Thus, the air in the apparatus was constantly changed and deodorized. Second, the entire apparatus was sprayed with "Wizard" brand kitchen spray before each trial of Ss 1,6 , and 11 in each squad.

\section{RESULTS}

Figure 1 presents mean speeds (meters/sec) for Groups $0-0,2-0$, and $8-0$ for the start measure (the measure which had previously yielded the most pronounced NCEs), while Fig. 2 presents mean speeds for Groups 2-2 and 8-8 for the sta ${ }_{1}$ t measure. Analyses of variance comparing Groups 2-0, 8-0, 2-2, and 8-8 were performed on the data for all measures from Days 8-9, since this appeared to be the point in training before which most of the growth in overall performance, but little discrimination, had occurred. Involved in these analyses were those groups that were confined to the 


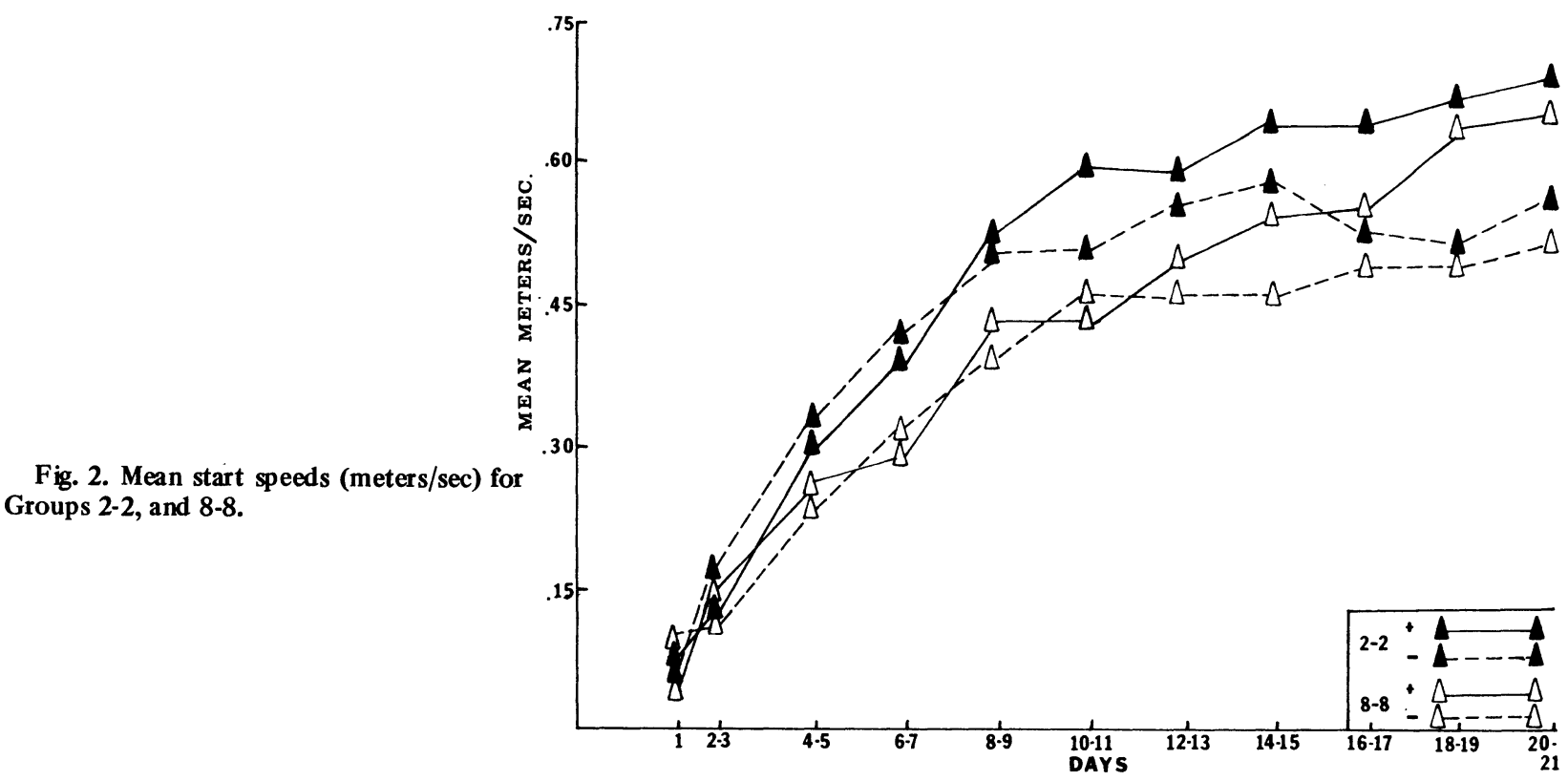

startbox for some period of time before a trial was begun. These analyses indicated that only the startbox confinement factor was significant and, further, that its significance $(\mathrm{F}=7.95, \mathrm{df}=1 / 64, \mathrm{p}<.01)$ was limited to the start measure. Thus, increasing startbox confinement time lowered starting speeds significantly. While the same trend clearly appeared in the other measures as well, it was not statistically reliable.

Similarly, analyses of variance were performed for Days 18-21 for Groups 2-0, 2-2, 8-0, and 8-8. The S+ vs S- factor was significant in all measures (start: $\mathrm{F}=52.00, \mathrm{df}=1 / 64, \mathrm{p}<.01 ;$ run: $\mathrm{F}=39.10, \mathrm{df}=1 / 64$, $\mathrm{p}<.01$; and goal: $\mathrm{F}=13.48, \mathrm{df}=1 / 64, \mathrm{p}<.01)$. The startbox confinement factor was significant $(F=4.17$, $\mathrm{df}=1 / 64, \mathrm{p}<.05)$ in the goal measure. No other significant effects were found. The statistical analyses support the graphical impression that, by the end of acquisition, differential reward caused all groups to run faster in $\mathrm{S}+$ than in $\mathrm{S}-$. However, the further impression that increasing confinement time in the startbox prior to performance lowered speed was statistically supported only in the goal measure.

The above analyses involved comparisons among only those groups that experienced a startbox confinement of some duration and thus excluded Group 0-0. Further analyses comparing Groups 0-0, 2-0, and 8-0 investigated the effect of confinement time with cue time held constant at $0 \mathrm{sec}$. The results of the analyses of Days 8-9 indicated that only the startbox confinement factor was significant. It was found to be significant in all three measures (start: $\mathrm{F}=9.61$, df $=2 / 48, \mathrm{p}<.01$; run: $\mathrm{F}=6.82$, df $=2 / 48, \mathrm{p}<.01:$ and goal: $\mathrm{F}=5.08, \mathrm{df}=$ $2 / 48, \mathrm{p}<.05)$. The analyses of Days $18-21$ indicated that both the startbox confinement factor (start: $\mathrm{F}=10.80, \mathrm{df}=2 / 48, \mathrm{p}<.01 ;$ run: $\mathrm{F}=7.83, \mathrm{df}=2 / 48$, $\mathrm{p}<.01$; and goal: $\mathrm{F}=5.15, \mathrm{df}=2 / 48, \mathrm{p}<.05)$ and the
S+ vs $S-$ factors (start: $F=20.52, \mathrm{df}=1 / 48, \mathrm{p}<.01$; run: $\mathrm{F}=12.97, \mathrm{df}=1 / 48, \mathrm{p}<.01$; and goal: $\mathrm{F}=17.20$, $\mathrm{df}=1 / 48, \mathrm{p}<.01)$ were significant in all three measures. Again, these analyses statistically support the graphical impressions that increasing confinement time lowers performance, and that differential responding developed by the end of the acquisition phase.

\section{DISCUSSION}

The most striking result of the present study is the complete absence of an effect of presenting the discriminative cues in the startbox prior to the running response. Appropriate and about equal differential responding developed in all groups. This is striking because previous studies have shown the importance of such preresponse cues.

However, before it is concluded that these data are simply discrepant, it should be noted that in the present study the development of differential responding in groups $(0-0,2-0,8-0)$ that should have been susceptible to strong depression of performance to $\mathrm{S}-$ is markedly different from differential responding in studies demonstrating the importance of pre response cues. Specifically, when it has been shown that preresponse cues attenuate depression of $\mathrm{S}$ - speed, speed has been sharply depressed in the absence of cues, and the learning function for S- has been characteristically nonmonotonic, at least in the starting speed, rising initially and then dropping quickly. In contrast, the present $\mathrm{S}-$ functions increased monotonically (with Group 0-0 showing only a slight nonmonotonic trend) and were not greatly depressed. That is, in the present study there was discrimination, but for unknown reasons there was no sharp depression of $S$ - performance even without preresponse cues. Therefore, there was little depression of $\mathrm{S}$ - for preresponse cues to attenuate.

Considering this study in conjunction with previous studies on the effect of preresponse cues, it is tempting to conclude that (a) simple discriminative responding and (b) discriminative responding that displays a sharp $\mathrm{S}$ - depression involve different and separable processes, in that the $S$ - depression does not necessarily accompany discrimination of this type. Furthermore, assuming the $\mathrm{S}-$ depression is a result of frustrative emotional processes, these results invite the conclusion that frustration is 
not necessarily aroused in differential reward training, but that differential responding can result solely from "pure," nonemotional processes of discrimination, differential habit or incentive formation, or whatever.

It will be noted that the relationship between frustration and instrumental discrimination has been a problem of fundamental theoretical concern (Amsel, 1962; Daly, 1971). On this view, the presence or absence of preresponse cues would be seen as important only in-so-far as frustration overlays or accompanies the basic discrimination, because only the frustration reaction would be assumed to follow a temporal course of being maximal following presentation of $\mathrm{S}-$ and diminishing thereafter with time (see Ludvigson \& Gay, 1967). Viewed thusly, the present results are a case of nonfrustrative differential reward conditioning; why frustration was not present is an intriguing empirical question.

Another interesting aspect of the data of the present experiment concerns the startbox confinement factor. Following the initial rise in speed, but prior to the development of any discrimination (Days 8-9), it can be seen that longer startbox confinement times had the effect of decreasing performance. By the end of acquisition the effect of startbox confinement appears, at least graphically, to have become more pronounced. These results do not agree with those of Kimmel and McGinnis (1966) who found that short delays ( 2 and $4 \mathrm{sec}$ ) in the startbox had no effect on acquistion performance. However, their finding was reported after only 20 training trials. Had these investigators extended the training period or used a third group receiving a longer delay, such as the 8-sec groups used in the present experiment, it is possible that a significant startbox confinement effect might have been demonstrated.

\section{REFERENCES}

Amsel, A. Frustrative nonreward in partial reinforcement and discrimination learning: Some recent history and a theoretical extension. Psychological R eview, 1962, 69, 306-328.

Daly, H. B. Evidence for frustration during discrimination learning. Journal of Experimental Psychology, 1971, 88, 205-215.

Davis, S. F., Gilbert, R. F., \& Seaver, W. E. Stimulus onset and its effect on $S+$ and $S$ performance in differential conditioning. Psychonomic Science, 1971, 25, 29-31.

Kimmel, H. D., \& McGinnis, N. H. Frustration effect following changed S-R temporal relations. Psychonomic Science, 1966 , 5, 333-334

Ludvigson, H. W., \& Gay, R. A. An investigation of conditions determining contrast effects in differential reward conditioning. Journal of Experimental Psychology, 1967, 75, 37-42.

Ludvigson, H. W., \& Sytsma, D. The sweet smell of success: Apparent double alternation in the rat. Psychonomic Science, 1967, 9, 283-284.

Peckham, R. H., \& Amsel, A. Within-subjects demonstration of a relationship between frustration and magnitude of reward in a differential magnitude of reward discrimination. Journal of Experimental Psychology, 1967, 73, 187-195.

(R eceived for publication July $25,1974$. ) 